\title{
TENTANG SEJARAH TOSHIBA
}

\section{ALDI SUHENDAR 185100010}

Fakultas Komputer

aldisuhendar.student@umitra.ac.id

\begin{abstract}
Toshiba adalah perusahaan pemroduksi elektronik teknologi tinggi yang bermarkas di Tokyo, Jepang. Toshiba dibentuk pada tahun 1939, merupakan hasil merger dari dua perusahaan. Tokyo Denki adalah perusahaan yang bergerak dibidang consumer goods dan perusahaan mesin Shibaura Seisakusho. Mengambil beberapa huruf didepan dari masing-masing perusahaan "TO" dan "SHIBa" maka lahirlah merek Toshiba. Pada tahun 1984 perusahaan itu resmi berubah menjadi Toshiba Corporation. Grup ini makin kuat melalui pertumbuhan internal dan melalui akuisisi perusahaan rekayasa alat berat dan perusahaan industri primer pada 1940-an dan 1950-an. Kemudian pada 1970-an dan seterusnya, anak perusahaan mulai didirikan, yaitu: grup Toshiba Lighting \& Teknologi (1989), Toshiba Carrier Corporation (1999), Toshiba Elevator \& Building System Corp (2001), Toshiba Solutions Corp (2003), Toshiba Medical Systems Corp (2003) dan Toshiba Materials Co Ltd (2003).
\end{abstract}

Kata Kunci : TENTANG SEJARAH PERUSAHAAN TOSHIBA 


\section{A. PENDAHULUAN}

Toshiba adalah perusahaan Jepang yang memproduksi dan memasarkan berbagai peralatan listrik dan produk elektronik yang canggih, yang berkantor pusat di Tokyo, Jepang Perkembangan teknologi menjadikan banyak perusahaan melakukan banyak pembaharuan untuk memenuhi kebutuhan para masyarakat. Berbagai jenis

teknologi ditawarkan guna untuk memenuhi kebutuhan serta memberikan fasilitas yang belum pernah ada..

\section{A. PEMBAHASAN / STUDI KASUS}

Toshiba secara pasti meningkat di dalam penjualannya dan mengembangkan produk-produk yang inovatif hingga dikenal di seluruh dunia. Sebagai salah satu merek ternama di Jepang, Toshiba telah menerima berbagai penghargaan karena menjadi pionir dalam menemukan radar, oven microwavge, sistem MRI, laptop, dan DVD. Pada tahun 2015, Toshiba telah mengoperasikan seluruh bisnisnya dalam skala golbal di berbagai industri, termasuk semikonduktor, elektronik, infrastruktur, peralatan rumah tangga dan alat-alat kesehatan dengan penjualan yang mencapai lebih dari 63 milyar dolar Amerika dan telah mempekerjakan lebih dari 200.000 karyawan di seluruh dunia.Kualitas seluruh produk maupun jasa yang ditawarkan oleh Toshiba menempatkan perusahaan tersebut dalam 10 perusahaan terbesar di Jepang.
Toshiba memproduksi semua jenis laptop, dari model Libretto yang lucu dan ultra portabel sampai model multimedia Qosmio keren. Laptop Toshiba juga populer di Amerika dan Eropa. Salah satu Model Laptop Toshiba yang ada dipasaran ;

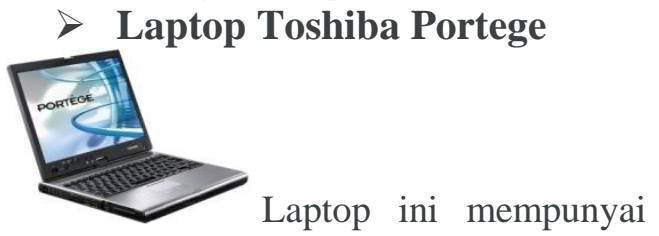
kecepatan pemrosesan yang bagus, memiliki hard drive dengan kapasitas yang cukup untuk menyimpan dokumen, file media digital, dan software produktivitas. Selain itu, dia juga didukung grafis yang memukau, dan koneksi Internet dengan kecepatan tinggi dengan design yang menawan dan dapat dibanggakan pemakainya.

Namun sayangnya pada bulan Mei 2015, Toshiba mengejutkan seluruh dunia saat menyatakan bahwa perusahaannya tengah melakukan investigasi atas skandal akuntansi internal dan harus merevisi perhitungan laba dalam 3 tahun terakhir. Pengumuman tersebut sangat tidak disangka karena Toshiba telah menjadi lambang perusahaan Jepang yang sangat kuat. Setelah diinvestigasi secara menyeluruh, diketahuilah bahwa Toshiba telah kesulitan mencapai target keuntungan bisnis sejak tahun 2008 di mana pada saat tengah terjadi krisis global. Krisis tersebut juga melanda usaha Toshiba hingga akhirnya Toshiba melakukan suatu kebohongan melalui accounting fraud senilai 1.22 milyar dolar Amerika.Tindakan ini dilakukan dengan berbagai upaya sehingga 
menghasilkan laba yang tidak sesuai dengan realita.

Pada tanggal 21 Juli 2015, ceo Hisao Tanaka mengumumkan pengunduran dirinya dan delapan pimpinan lain termasuk dua ceo sebelumnya terkait skandal akunting yang ia sebut sebagai peristiwa yang paling merusak merek Toshiba sepanjang 140 tahun sejarah berdirinya Toshiba. Namun hingga awal 2017 Toshiba masih mencoba bangkit kembali dari dampak buruk skandal di tahun 2015.

\section{B. ID SECURITY QWTD4452377-ASP-5244107}

\section{KESIMPULAN}

Toshiba merupakan perusahaan asal jepang yang bergerak dibidang teknologi. Toshiba adalah perusaan yang memproduksi dan memasarkan berbagai alat elektronik seperti laptop,tv dan lain lainnya. Namun pada tahun 2015 terjadi masalah internal pada perusaan toshiba sehingga membuat perusahaan terpuruk. Namun pada tahun 2017 Toshiba telah bangkit kembali.

\section{DISKUSI}

Bagaimana Pendapat Anda Tentang Artikel Ini ?
Riski : Menurut saya artikel ini cukup baik. Karena mudah dipahami.

Apakah kelebihan artikel ini? Cici : Menurut saya artikel ini Memberi penjelasan cukup baik sehingga mudah dipahami.

Apa fungsi artikel ini ?

Suhandry : Menurut saya artikel ini dapat membantu mengetahui tentang sejarah perusahaan Toshiba.

\section{E. REFERENCE}

[1] O. M. Febriani and A. S. Putra, "Sistem Informasi Monitoring Inventori Barang Pada Balai Riset Standardisasi Industri Bandar Lampung," J. Inform., vol. 13, no. 1, pp. 90-98, 2014.

[2] A. S. Putra, "Paperplain: Execution Fundamental Create Application With Borland Delphi 7.0 University Of Mitra Indonesia," 2018.

[3] A. S. Putra, "2018 Artikel Struktur Data, Audit Dan Jaringan Komputer," 2018.

[4] A. S. Putra, "ALIAS MANAGER USED IN DATABASE DESKTOP STUDI CASE DB DEMOS."

$\begin{array}{lr}\text { A. S. } & \text { Putra, } \\ \text { "COMPREHENSIVE } & \text { SET OF } \\ \text { PROFESSIONAL } & \text { FOR }\end{array}$



[6] A. S. Putra, "DATA ORIENTED RECOGNITION IN BORLAND DELPHI 7.0."

[7] A. S. Putra, "EMBARCADERO DELPHI XE 2 IN GPUPOWERED FIREMONKEY APPLICATION."

[8] A. S. Putra, "HAK ATAS KEKAYAAN INTELEKTUAL DALAM DUNIA TEKNOLOGY BERBASIS REVOLUSI INDUSTRI 4.0."

[9] A. S. Putra, "IMPLEMENTASI PERATURAN PERUNDANGAN UU. NO 31 TAHUN 2000 TENTANG DESAIN INDUSTRI BERBASIS INFORMATION TECHNOLOGY."

[10] A. S. Putra, "IMPLEMENTATION OF PARADOX DBASE."

[11] A. S. Putra, "IMPLEMENTATION OF TRADE SECRET CASE STUDY SAMSUNG MOBILE PHONE."

[12] A. S. Putra, "IMPLEMENTATION PATENT FOR APPLICATION WEB BASED CASE STUDI WWW. PUBLIKLAMPUNG. COM."

[13] A.

"IMPLEMENTATION

SYSTEM FIRST TO INVENT IN DIGITALLY INDUSTRY."

[14] A. S. Putra, "MANUAL REPORT \& INTEGRATED DEVELOPMENT

ENVIRONMENT BORLAND DELPHI 7.0."

[15] A. S. Putra, "PATENT AS RELEVAN

SUPPORT
RESEARCH."

[16] A. S. Putra, "PATENT FOR RESEARCH STUDY CASE OF APPLE. Inc."

[17] A. S. Putra, "PATENT PROTECTION FOR APPLICATION INVENT."

[18] A. S. Putra, "QUICK REPORT IN PROPERTY PROGRAMMING."

[19] A. S. Putra, "REVIEW CIRCUIT LAYOUT COMPONENT

REQUIREMENT ON ASUS NOTEBOOK."

[20] A. S. Putra, "REVIEW TRADEMARK PATENT FOR INDUSTRIAL TECHNOLOGY BASED 4.0."

[21] A. S. Putra, "TOOLBAR COMPONENT PALLETTE IN OBJECT ORIENTED PROGRAMMING."

[22] A. S. Putra, "WORKING DIRECTORY SET FOR PARADOX 7."

[23] A. S. Putra, "ZQUERY CONNECTION

IMPLEMENTED

PROGRAMMING STUDI CASE PT. BANK BCA Tbk."

[24] A. S. Putra, D. R. Aryanti, and I. Hartati, "Metode SAW (Simple Additive Weighting) sebagai Sistem Pendukung Keputusan Guru Berprestasi (Studi Kasus: SMK Global Surya)," in Prosiding Seminar Nasional Darmajaya, 2018, vol. 1, no. 1, pp. 85-97.

[25] A. S. Putra and O. M. Febriani, "Knowledge Management Online Application in PDAM Lampung Province," in Prosiding International 
conference on Information

Technology and Business

(ICITB), 2018, pp. 181-187.

[26] A. S. Putra, O. M. Febriani, and B. Bachry, "Implementasi Genetic Fuzzy System Untuk Mengidentifikasi Hasil Curian Kendaraan Bermotor Di Polda Lampung," SIMADA (Jurnal Sist. Inf. dan Manaj. Basis Data), vol. 1, no. 1, pp. 21-30, 2018.

[27] A. S. Putra, H. Sukri, and K. Zuhri, "Sistem Monitoring Realtime Jaringan Irigasi Desa (JIDES) Dengan Konsep Jaringan Sensor Nirkabel," IJEIS (Indonesian J. Electron. Instrum. Syst., vol. 8, no. 2, pp. 221-232.

[28] D. P. Sari, O. M. Febriani, and A. S. Putra, "Perancangan Sistem Informasi SDM Berprestasi pada SD Global Surya," in Prosiding Seminar Nasional Darmajaya, 2018, vol. 1, no. 1, pp. 289-294. 